\title{
Utilização de subprodutos da indústria de biodiesel na alimentação de ruminantes
}

\section{Adibe Luiz Abdalla ${ }^{1}$, José Cleto da Silva Filho ${ }^{2}$ Antonio Roberto de Godoi ${ }^{3}$, Carolina de Almeida Carmo ${ }^{3}$, José Luiz de Paula Eduardo ${ }^{4}$}

\author{
1Laboratório de Nutrição Animal - Centro de Energia Nuclear na Agricultura, USP - Piracicaba, SP. \\ Departamento de Zootecnia - Universidade Federal de Lavras - Lavras, MG \\ ${ }^{3}$ Techenergy Tecnologias - Piracicaba, SP. \\ ${ }^{4}$ Labore - Piracicaba, SP.
}

RESUMO: Com a introdução de óleo vegetal na cadeia produtiva do biocombustível no Brasil, é esperado o aumento da demanda por plantas oleaginosas e oferta de fibras vegetais resultantes da extração do óleo. Considerando a alimentação animal como elo entre a produção de biodiesel e a pecuária, propomos o estudo da utilização de subprodutos destes empreendimentos na alimentação visando aumentar a produtividade e diminuir a emissão de gases de efeito estufa pelos animais, gerando créditos de carbono e atendendo ao interesse da iniciativa privada. A técnica de produção de gases in vitro tem sido utilizada no LANA-CENA/USP com a finalidade de estudar o efeito de alimentos que possuem metabólitos secundários bioativos, na fermentação ruminal e degradabilidade da matéria orgânica (MOVD), bem como, no estudo da produção de metano. Resultados recentes mostraram que a substituição total do farelo de soja por tortas de algodão, dendê, mamona e pinhão manso proporcionou menor produção total de gases; e que a produção de metano foi significativamente afetada pela inclusão das tortas, sendo que o farelo de soja apresentou produção de metano de 15,3 mL/g MOVD. Diversos trabalhos mostram que as tortas e farelos apresentam características nutricionais adequadas para inclusão na dieta de ruminantes, entretanto, estudos criteriosos desses materiais enquanto matérias-primas para ração animal são necessários para avaliar possíveis efeitos deletérios devido à presença de metabólitos bioativos. Através de análises de cromatografia de alta resolução, podem ser identificadas essas substâncias que, em condições tropicais podem não apresentar a mesma toxicidade. A introdução de tortas com elevado teor de gordura nas dietas de ruminantes pode auxiliar na mitigação de metano entérico, e a produção de algumas oleaginosas pode contribuir com o seqüestro de carbono pelos solos de Cerrado na recuperação de pastagens, reduzindo a necessidade de desmatamentos.

Palavras-chave: características nutricionais, mitigação de gases de efeito estufa, metabólitos bioativos

ABSTRACT: With the introduction of vegetable oil in the bio-fuel productive chain in Brazil, the increase in the demand of oleaginous plants is expected as well as the offer of the resulting vegetable fibers from the extraction of the oil. Considering the animal feeding as link between the biodiesel production and the livestock, we propose the study of the use of by-products of these enterprises in the feeding system seeking to increase the productivity and to reduce the emission of greenhouse gases from the animals, generating carbon credits and assisting to the interest of the private initiative. The in vitro gas technique has been used at LANA-CENA/USP with the purpose of studying the effect of feeds containing secondary bioactive metabolites upon the ruminal fermentation and organic matter degradability (MOVD), as well as, in the study of methane production. The total substitution of the soybean meal for meals of cotton seed, palm oil, castor oil plant and jatropha provided less total gas production and the production of methane was affected significantly by the inclusion of the meals, with soybean meal presenting methane production of $15.3 \mathrm{~mL} / \mathrm{g}$ MOVD. Literature data also show that meals from biodiesel production present appropriate nutritional characteristics for inclusion in the diet of ruminant, however, discerning studies of those materials while raw materials for animal ration are necessary to evaluate possible harmful effects due to the presence of bioactive metabolites. Through analyses of high resolution chromatography, those metabolites may be identified. The introduction of meals with high fat content in the diets of ruminant can aid in the mitigation of enteric methane, and the production of some oleaginous plants can contribute with the sequestering of carbon for the Cerrado soils in the recovery of pastures, reducing the need of deforestations

Key words: nutritional characteristics, mitigation of greenhouse gases, bioactive metabolites

\section{Introdução}

A crescente preocupação mundial com o meio ambiente, juntamente com a busca por fontes de energia renováveis, coloca o biodiesel no centro das atenções e interesses. Diversos países, dentre eles o Brasil, procuram o caminho do domínio tecnológico desse biocombustível, tanto em nível agronômico como industrial, o que deverá provocar fortes impactos na economia brasileira e na política de inclusão social do país.
O biodiesel, por ser biodegradável, não tóxico e praticamente livre de enxofre e compostos aromáticos, é considerado combustível ecológico, podendo promover uma redução substancial na emissão de monóxido de carbono e de hidrocarbonetos quando em substituição ao diesel convencional no motor (Storck Biodiesel, 2008).

Há importantes aspectos envolvendo a cadeia do biodiesel no Brasil, destacando-se as questões relacionadas às matérias-primas e ao processo de produção industrial. Existe grande diversidade de plantas oleaginosas aptas a serem utilizadas e o 
desenvolvimento de processos industriais passa a fazer uso de catalisadores de última geração, em rotas totalmente etílicas, para a produção do biodiesel.

Atualmente discute-se a viabilidade econômica dos projetos de produção de biodiesel onde o tema custo de produção (custo agronômico e custo industrial) é tido como fator motivador ou inibidor de futuros empreendimentos nesse negócio; além de ser motivo de controvérsias entre especialistas, uma vez que não há estudo aprofundado que determine o impacto dos subprodutos do biodiesel no custo total de sua produção. Conforme estudo do CEPEA-ESALQ/USP, a análise de custos do biodiesel deixou clara a grande importância dos subprodutos na contabilidade final da indústria integrada do biodiesel (Barros et al., 2006).

O biodiesel é fabricado através de transesterificação, na qual a glicerina é separada da gordura ou óleo vegetal. O processo gera dois produtos: ésteres (o nome químico do biodiesel) e glicerina (produto valorizado no mercado de sabões); além de coprodutos (torta, farelo etc.) que podem constituir outras fontes de renda importantes para os produtores.

Geralmente, a torta ou farelo gerado na extração do óleo não passam por processo de agregação de valor porque são desconhecidas as suas potencialidades nutricionais e econômicas, salvo algumas exceções como soja, algodão e girassol. Associado a esse fato, são também desconhecidas as possibilidades de obtenção de receitas advindas do mercado de crédito de carbono, relativas à redução da emissão de gás metano passíveis de ocorrer quando se utilizam rações contendo essas oleaginosas.

De acordo com estudos recentes na Austrália e Canadá, para cada $1 \%$ de acréscimo de gordura na dieta de ruminantes, pode se reduzir em até $6 \%$ a quantidade de metano produzido por Kg de matéria seca consumida (Grainger, 2008).

\section{Produção de biodiesel}

O biodiesel é o produto de transformação química do óleo ou gordura (vegetal ou animal) por adição de álcool (metanol ou etanol) na presença de catalisador ( $\mathrm{NaOH}$ ou $\mathrm{KOH})$ (Universidade de Açores, 2008). A produção de biodiesel no Brasil vem crescendo significativamente nos últimos anos (Figura 1), sendo as estimativas de produção para 2008 (1 bilhão de L), reflexo da legislação.

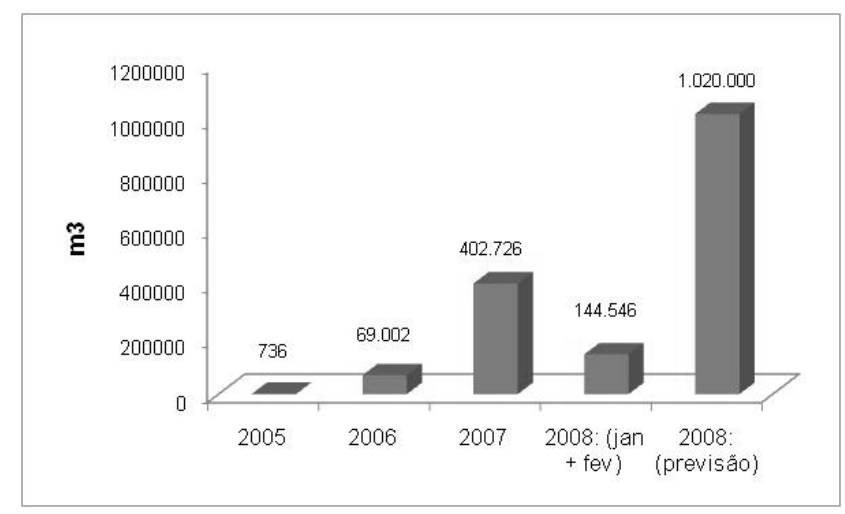

Figura 1 - Produção de biodiesel no Brasil.

O governo federal, por meio do Programa Nacional de Produção e Uso de Biodiesel, autoriza a adição de $2 \%$ deste combustível ao óleo diesel de origem fóssil (Brasil, 2003), sendo que a partir de junho de 2008 esta adição passou a ser de $3 \%$. A partir de 2013, serão necessários aproximadamente 2,5 bilhões de litros de biodiesel para atender à Lei 11097/2005, quando a adição de biodiesel ao óleo diesel deverá ser de 5\%. A experiência de utilização do biodiesel no mercado de combustível tem se dado em quatro níveis de concentração: puro (B100), misturas (B20 - B30), aditivo (B5) e aditivo lubrificante (B2) (Storck Biodiesel, 2008).

Atualmente a produção de biodiesel ainda está dependente das produtoras de óleo vegetal ${ }^{1}$, sendo a produção por matéria prima correspondente a $81 \%$ à soja, $8 \%$ ao caroço de algodão, $5 \%$ ao sebo, $4 \%$ à palma, $2 \%$ à mamona e $1 \%$ ao girassol.

A produção de tortas a partir das oleaginosas, correspondente ao biodiesel a ser produzido em 2008, pode ser estimada em 3.676.566 $\mathrm{T}$ (total), sendo a produção de acordo com a oleaginosa de $3.261 .316 \mathrm{~T}$ de soja, $318.240 \mathrm{~T}$ de algodão, $61.200 \mathrm{~T}$ de dendê, 23.182 $\mathrm{T}$ de mamona e $12.629 \mathrm{~T}$ de girassol, considerando a densidade igual a 1 (um) para o óleo e para as tortas de todas as oleaginosas. O pinhão manso (Jatropha curcas) ainda não teve a produção iniciada (Storck Biodiesel, 2008; BiodieselBr.com; Petrobio, 2005). A

\footnotetext{
${ }^{1}$ Techenergy Tequinologias, dados não publicados.
} 
capacidade autorizada para produção de biodiesel é de $2.537 .000 \mathrm{~m}^{3}$ (249\% maior). Considerando as mesmas proporções, o Brasil poderá estar produzindo cerca de 8,9 bilhões de T de torta.

Atualmente, os principais empregos das tortas, são adubação orgânica, geração de energia e alimentação animal. Considerando a alimentação animal como o elo entre a produção de biodiesel e a pecuária, a utilização deste subproduto na alimentação de ruminantes visa aumentar a produtividade e gerar menor emissão de gases de efeito estufa pelos animais, gerando créditos de carbono e atendendo ao interesse da iniciativa privada.

De acordo com Grainger (2008), estimativas de inclusão extra de $2 \%$ de gordura, através da utilização de tortas ou farelos de oleaginosas, na dieta de bovinos de leite da Austrália, levaria a uma redução de 12 \% na emissão de metano, o que em termos econômicos em um comércio de abatimento de $\mathrm{CO}_{2}$, valeria aproximadamente AU\$ 30.5 M para a indústria leiteria.

\section{Subprodutos do biodiesel na alimentação animal:}

O Brasil apresenta grandes possibilidades de oleaginosas para produção de biodiesel devido a sua diversidade climática e de ecossistemas. As principais oleaginosas cultiváveis no Brasil que poderiam ser utilizadas para a fabricação de biodiesel são a soja (Glycine max), o girassol (Helianthus annuus), a mamona (Ricinus communis), o dendê (Elaeis guineensis), o pinhão-manso (Jatropha curcas), o nabo forrageiro (Raphanus sativus), o algodão (Gossypium spp. L.), o amendoim (Arachis hypogaea), a canola (Brassica napus), o gergelim (Sesamum arientale), o babaçu (Orrbignya speciosa) e a macaúba (Acrocomia aculeata) (Storck Biodiesel, 2008; BiodieselBr.com, 2008; Petrobio, 2005).

A glicerina, também produzido na cadeia do biodiesel, pode ser utilizada na alimentação animal; entretanto o produto é bastante valorizado no mercado de sabões. Trabalho recente para avaliar a adição de níveis crescentes de glicerina na dieta de suínos em crescimento vem sendo desenvolvido e os resultados iniciais indicam que a glicerina pode ser utilizada como ingrediente energético de rações de suínos em crescimento e terminação até o nível de $9 \%$ sem afetar o desempenho e as características de carcaça dos animais
(Berenchtein, 2008²). Em aves, o glicerol pode ser utilizado como fonte de energia em dietas de alta produção, entretanto cuidados devem ser tomados em relação à possível concentração residual de metanol (Cerrate et al., 2006). Em ruminantes, Schröder \& Südekum (1999) utilizaram o glicerol como substância glicogênica em dieta para vacas com alta produção de leite. Os autores concluem que o glicerol melhorou o suprimento de energia e auxiliou na prevenção de problemas de cetose.

\section{Características de culturas oleaginosas quanto ao teor de óleo, produtividade e produção de óleo}

A maioria das tortas ou farelos das oleaginosas que vêm sendo utilizadas para produção de biodiesel no Brasil são passíveis de utilização na alimentação animal, porém, cada uma com suas particularidades no que diz respeito a cuidados antes de serem fornecidas aos animais devido a alguns fatores tóxicos ou antinutricionais que possuem, quantidades máximas dentro da formulação das dietas dos animais e práticas de armazenamento.

Na Tabela 1 são apresentadas as características de algumas plantas oleaginosas com potencial para produção de biodiesel no Brasil. Em todas as regiões do país existem culturas com vocações agrícolas que podem ser consideradas como matéria prima compatível com os objetivos do programa do biodiesel (BiodieselBr.com).

A maioria das culturas é de ciclo relativamente curto (90 a 180 d), potencializando a utilização em rotação de culturas, reformas de canaviais e de áreas degradadas (pastagens), contribuindo ainda com o elevado potencial de seqüestro de carbono pelos solos quando da prática de plantio direto (Bayer et al., 2006)

O teor médio de óleo das oleaginosas estudadas é de 31\%, com uma produtividade média estimada de $4.000 \mathrm{~kg} / \mathrm{ha} /$ ano. Considerando a relação torta/óleo por oleaginosa (média) igual a 1,8 (aproximada, já que varia por processo de extração, variedade, cultura, eficiência de processo, dentre outros), o país apresenta um potencial de produção de tortas e ou farelos na ordem de $14.746 \mathrm{~kg} / \mathrm{ha} / \mathrm{ano}$.

\footnotetext{
${ }^{2}$ Informação fornecida por Berenchtein em maio de 2008.
} 
Tabela 1 - Teor de óleo (\%), produtividade (Kg/ha/ano) e produção de óleo $(\mathrm{Kg} / \mathrm{ha} / \mathrm{ano})$ de algumas oleaginosas com potencial para produção de biodiesel no Brasil

\begin{tabular}{|c|c|c|c|c|c|}
\hline Espécie & Distribuição & Ciclo & $\begin{array}{l}\text { Teor de } \\
\text { óleo (\%) }\end{array}$ & $\begin{array}{l}\text { Produtividade } \\
\text { (kg/ha/ano) }\end{array}$ & $\begin{array}{c}\text { Produção } \\
\text { de óleo } \\
\text { (kg/ha/ano) }\end{array}$ \\
\hline Amendoim & NE, CO & $\begin{array}{l}120- \\
180 \mathrm{~d}\end{array}$ & 49 & 1800 & 882 \\
\hline Babaçu & $\mathrm{N}, \mathrm{NE}$ & $12 \mathrm{~m}$ & 4 & 15000 & 600 \\
\hline Canola & S & $\begin{array}{l}130- \\
140 \mathrm{~d}\end{array}$ & 38 & 1800 & 684 \\
\hline $\begin{array}{l}\text { Caroço de } \\
\text { algodão }\end{array}$ & $\begin{array}{l}\text { N, NE, CO, } \\
\quad \text { S, SE }\end{array}$ & $160 \mathrm{~d}$ & 15 & 1800 & 270 \\
\hline Dendê/Palma & $\mathrm{N}$ & $12 \mathrm{~m}$ & 20 & 10000 & 2000 \\
\hline Gergelim & NE, CS & $\begin{array}{l}120- \\
180 \mathrm{~d}\end{array}$ & 39 & 1000 & 390 \\
\hline Girassol & S, SE, CO & $\begin{array}{c}90- \\
140 \mathrm{~d}\end{array}$ & 42 & 1600 & 672 \\
\hline Mamona & $\mathrm{NE}$ & $\begin{array}{l}100- \\
300 \mathrm{~d}\end{array}$ & 44 & 1500 & 660 \\
\hline $\begin{array}{l}\text { Nabo } \\
\text { forrageiro }\end{array}$ & S, SE, CO & $\begin{array}{l}100- \\
120 \mathrm{~d}\end{array}$ & 29 & 500 & 145 \\
\hline $\begin{array}{l}\text { Pinhão- } \\
\text { manso }\end{array}$ & NE, SE, CO & perene & 40 & 8000 & 3200 \\
\hline Soja & $\mathrm{CO}$ & $\begin{array}{c}\mathrm{CO}, \\
\text { SE, S }\end{array}$ & 19 & 2200 & 418 \\
\hline
\end{tabular}

\section{Composição nutricional das tortas e farelos}

Vários trabalhos de investigação da qualidade nutricional das tortas e farelos têm mostrado o potencial de utilização deste material na alimentação dos animais (Balbinot et al., 2006; Albuquerque, 2006; Neiva Junior et al., 2007; Silva et al., 2005a, 2005b; Arriel et al., 1999; Costa et al., 2004; Evangelista, et al., 2007; Barbosa, 2004; Valadares Filho et al., 2002). Na Tabela 2 é apresentada uma compilação dos teores de proteína bruta (PB), extrato etéreo (EE) e fibra bruta (FB) das tortas pesquisadas.

O conteúdo protéico destas tortas é relativamente alto (35\%), com variação de 14 a 60\%, sugerindo a utilização como fonte de proteína para os animais (Jardim, 1976). O teor de gordura (EE) também varia consideravelmente (3 a 24\%) o que pode ser outro benefício para os ruminantes, considerando que a inclusão de óleo na dieta pode auxiliar na mitigação de metano entérico (Grainger, 2008).

O teor de fibra é relativamente baixo (20\%) o que corrobora em conferir a essas tortas, serem classificadas como alimento concentrado (Morrison, 1966), rico em nutrientes (mínimo de 63\% de nutrientes digestíveis totais estimado de acordo com Kearl, 1982).
Tabela 2 - Teores de proteína bruta, extrato etéreo e fibra bruta (\% em base seca) de algumas tortas de oleaginosas com potencial para produção de biodiesel no Brasil

\begin{tabular}{|c|c|c|c|c|c|c|}
\hline \multirow{2}{*}{ Espécie } & \multicolumn{2}{|c|}{ Proteína Bruta } & \multicolumn{2}{|c|}{ Extrato etéreo } & \multicolumn{2}{|c|}{ Fibra bruta } \\
\hline & $\min$ & $\max$ & $\min$ & $\max$ & $\min$ & $\max$ \\
\hline Amendoim & 41 & 45 & 8 & 9 & 14 & 15 \\
\hline Babaçu & 18 & 20 & 7 & 8 & 26 & 29 \\
\hline Canola & 32 & 36 & 22 & 24 & 7 & 8 \\
\hline $\begin{array}{l}\text { Caroço de } \\
\text { algodão }\end{array}$ & 42 & 47 & 3 & 3 & 10 & 11 \\
\hline Dendê/Palma & 14 & 15 & 6 & 7 & 38 & 43 \\
\hline Gergelim & 36 & 40 & 12 & 13 & 5 & 5 \\
\hline Girassol & 20 & 22 & 20 & 22 & 21 & 23 \\
\hline Mamona & 39 & 43 & 4 & 4 & 18 & 20 \\
\hline $\begin{array}{c}\text { Nabo } \\
\text { forrageiro }\end{array}$ & 34 & 38 & 22 & 24 & 19 & 21 \\
\hline $\begin{array}{c}\text { Pinhão- } \\
\text { manso }\end{array}$ & 25 & 60 & 4 & 12 & 40 & 45 \\
\hline Soja & 42 & 47 & 3 & 4 & 7 & 8 \\
\hline Média & & & & & & \\
\hline
\end{tabular}

Um dos pontos críticos da utilização das tortas e farelos na alimentação animal é a infestação póscolheita pelo fungo Aspergillus flavus que produz toxina de alta letalidade (hepatotóxica, cancerígena e teratogênica), a aflatoxina, entretanto cuidados na colheita e armazenagem reduzem consideravelmente os problemas advindos da infestação.

Vários desses subprodutos apresentam fatores antinutricionais ou compostos bioativos específicos, desde agentes goitrogênios, glucosinolatos, ácido fítico, gossipol, tanino e saponinas, até compostos altamente tóxicos, como no caso do forbol encontrado em tortas de pinhão manso (Makkar et al., 1998; Makkar \& Becker, 1999). Entretanto alguns desses compostos são termo-lábeis e o desenvolvimento de variedades livres têm favorecido a introdução das tortas e farelos na dieta de ruminantes.

Para investigar e quantificar a presença dos metabólitos secundários bioativos nas tortas e farelos, é possível proceder a extração com metanol e /ou solução de acetona e o extrato analisado em cromatografia líquida de alta eficiência (CLAE) conforme metodologia específica para ester de forbol (Makkar \& Becker, 1999), gossipol (Cai et al., 2004), ricina (Reyes \& Koda, 2001) e flavonóides (Pekkarinen et al., 1999). 


\section{Aplicação de tortas e farelos em dietas para ruminantes}

O farelo de amendoim tem sido usado experimentalmente em dietas para ruminantes. Paziani et al. (2001) compararam o farelo de amendoim com o glúten de milho como fonte protéica em dietas com milho desintegrado com palha e sabugo e os autores concluíram que as fontes protéicas não afetaram a digestibilidade das dietas nem a degradação ruminal do amido.

Trabalhos recentes têm demonstrado o potencial de utilização do farelo de babaçu em substituição ao farelo de soja em dietas para ruminantes. Almeida (2005) em estudo com vacas leiteiras verificou que a utilização de farelo de babaçu promoveu um aumento na produção de leite e melhor viabilidade econômica, quando incluído em $20 \%$.

Sousa Junior et al. (2007) avaliaram a digestibilidade in vivo da matéria seca (MS) e proteína bruta (PB) de rações contendo farelo de babaçu para ovinos em terminação e concluíram que a inclusão, para animais com exigências energéticas elevadas, pode resultar em menor desempenho.

O farelo de algodão vem sendo utilizado em rações para ruminantes, substituindo o farelo de soja parcial ou totalmente. Ribeiro et al. (2007) mostraram uma redução no ganho de peso na terminação de bovinos alimentados com farelo de algodão, entretanto a fonte protéica (farelo de soja ou farelo de algodão) não afetou a qualidade da carcaça. De acordo com Pina et al. (2006) o farelo de algodão com $38 \%$ de PB pode ser utilizado para vacas leiteira de alta produção (25 $\mathrm{Kg} / \mathrm{d})$ quando utilizada a silagem de milho como volumoso na proporção de $60 \%$ da dieta.

A inclusão de torta de dendê em até 30\% de substituição parcial ao milho e farelo de soja, no concentrado de cabras em lactação, não afetou a digestibilidade aparente da MS da ração em trabalho de Silva et al. (2005a). Com o objetivo de avaliar a influência da utilização de farelo de cacau e de torta de dendê na alimentação de cabras leiteiras sobre o consumo e a produção de leite, Silva et al. (2005b) realizaram estudo, onde foi constatado que se pode substituir o concentrado contendo milho moído e farelo de soja por torta de dendê em até $19 \%$ da MS da dieta, sem reduzir o consumo e a produção de leite. Em ovinos, Carvalho et al. (2006) concluíram que a inclusão de torta de dendê em substituição ao farelo de soja não afetou parâmetros do comportamento ingestivo.

O farelo de girassol tem sido utilizado na alimentação animal e, de acordo com alguns estudos com ruminantes, o valor nutricional do farelo de girassol é equivalente ao farelo de soja e ao farelo de algodão (Vincent et al., 1990). Em trabalho de Garcia et al. (2006), os autores concluem que a inclusão de farelo de girassol na dieta não influenciou o consumo e o ganho de peso de bovinos leiteiros em crescimento; sendo o nível máximo de substituição do farelo de soja pelo de girassol de $45 \%$.

Entretanto, o farelo de girassol proporcionou menor ritmo de crescimento e características de carcaça inferiores, quando fornecido para cordeiros Santa Inês em confinamento, substituindo $50 \%$ e $100 \%$ do farelo de soja, conforme Louvadini et al. (2007).

Atualmente o principal uso da torta de mamona tem sido como adubo orgânico, que é um produto com baixo valor agregado se comparado com sua aplicação como alimento animal. Na alimentação animal, o uso é limitado pela presença de ricina e princípios alergênicos (Castor bean allergen - CBA), os quais podem passar ao leite em bovinos alimentados com a torta de mamona (Evangelista et al. 2007).

Por muito tempo se pensou que a atividade tóxica do pinhão manso fosse causada pela ação da lectina curcina, abundante nas sementes. Entretanto, vários trabalhos vêm contribuindo para demonstrar que a atividade tóxica das sementes e do óleo do pinhãomanso deve-se à presença de ésteres de forbol e não à da curcina. Os ésteres de forbol são uma complexa mistura de ésteres do forbol tetracíclico diterpeno, eles apresentam atividades carcinogênicas e ação inflamatória (Makkar et al., 1998; Makkar \& Becker, 1999). O farelo de pinhão-manso tem alto teor de proteína e após ser detoxificado pode ser utilizado na alimentação animal.

Van Cleef (2008) em ensaio in vitro comparando a adição de tortas de pinhão manso ou de nabo forrageiro em silagem de capim elefante, demonstrou uma redução na digestibilidade in vitro da matéria seca (DIVMS), verificada conforme a adição em níveis crescentes das tortas na silagem, sendo que para o pinhão manso, a redução foi mais acentuada. As 
silagens com nabo forrageiro apresentaram melhor qualidade e digestibilidade.

\section{Avaliação in vitro e in vivo de tortas de leguminosas visando mitigação de metano entérico}

A técnica de produção de gases in vitro, baseada na simulação das fermentações ruminais em frascos de vidro inoculados com microrganismos ruminais tem sido utilizada com a finalidade de estudar o efeito de alimentos que possuem fatores bioativos na fermentação ruminal e degradabilidade da matéria orgânica (Bueno et al., 2008), bem como, no estudo da produção de metano ruminal in vitro (Longo et al., 2006). Abdalla et al. (2007) estudando plantas taniníferas brasileiras mostraram correlação positiva entre o teor de tanino nas plantas e a redução na produção de metano, bem como o efeito das plantas sobre a abundância relativa da expressão gênica do DNA ruminal ampliado, usando pares de "primers" para bactérias, fungos, metanogêns, Ruminococcus flavefaciens e Fibrobacter succinogenes, após 24 hs de fermentação.

Longo et al. (2007) estudando plantas de mucuna (Styzolobium aterrimum e Styzolobium deeringianum), leucena (Leucaena leucocephala) e Sansão do Campo (Mimosa caesalpiniaefolia), concluíram que as plantas ricas em taninos afetaram negativamente a população de Fibrobacter succinogenes e propiciaram alterações na comunidade metanogênica utilizando DNA extraído do conteúdo dos frasco de fermentação in vitro.

A partir dos resultados in vitro, Abdalla et al. (2007), testando a inclusão do óleo de coco e planta taninífera (Mimosa caesalpiniaefolia) na dieta de ovinos em ensaio in vivo, demonstraram a redução na produção de metano entérico em relação à dieta padrão contendo feno de gramínea (70\%) e concentrado com milho $(7,5 \%)$ e farelo de soja (22,5\%).

Com o intuito de estudar a inclusão de tortas / farelos da cadeia do biodiesel na dieta de ruminantes visando a mitigação de metano, ensaios in vitro vêm sendo realizados no LANA-CENA/USP. Tortas de algodão, dendê, mamona e pinhão manso de procedências diferentes (I e II) foram incluídos na proporção de $25,50,75$ e $100 \%$ em dietas experimentais, substituindo o farelo de soja (Tabela 2).
Os substratos (500 mg) foram incubados a $39{ }^{\circ} \mathrm{C}$ por $24 \mathrm{hs}$ em frascos de vidro $(160 \mathrm{~mL})$ contendo 50 $\mathrm{mL}$ de solução tampão e $25 \mathrm{~mL}$ de inóculo ruminal de seis ovinos mantidos a pasto, recebendo $200 \mathrm{~g} / \mathrm{d}$ de concentrado contendo milho e farelo de soja. A pressão dos gases produzidos foi medida com um medidor de pressão (Pressdata 800, LANA/CENAUSP, Piracicaba/SP) a intervalos regulares (6, 14 e 24 horas) e a quantidade de gases produzidos foi estimada através de fórmula definida para as condições laboratoriais. Durante a medida da pressão, aproximadamente $3 \mathrm{~mL}$ de gases foram amostrados (tubo "vacutainer") de cada garrafa para posterior quantificação de metano. Após 24 horas de incubação a fermentação foi interrompida e o resíduo foi recuperado para determinação da degradabilidade in vitro da matéria orgânica.

Após o tratamento de cada garrafa com $75 \mathrm{~mL}$ de solução detergente ácido por 6 h, o conteúdo das garrafas foi filtrado em cadinhos sinterizados previamente pesados e lavados com água destilada quente. A extensão de desaparecimento da matéria orgânica após a fermentação foi obtida pela queima do resíduo retido nos cadinhos (MOVD) e o fator de partição foi determinado através da relação entre a MOVD e o volume total de gás produzido, sendo usado como um índice de eficiência de síntese microbiana.

Para quantificação do gás metano $\left(\mathrm{CH}_{4}\right)$, as amostras de gases colhidas durante o ensaio foram analisadas por cromatografia gasosa (Shimadzu GC2014) usando como padrão o gás metano (99\%), com detector a $240{ }^{\circ} \mathrm{C}$ e coluna Shincarbon a $60^{\circ} \mathrm{C}$.

Os resultados iniciais mostram que o teor médio de proteína nos substratos foi de 0,133 $\pm 0,0125 \mathrm{~g} / \mathrm{Kg}$ e a produção total de gases foi afetada pela inclusão das tortas em substituição ao farelo de soja.

Com exceção da torta de algodão, as demais produziram significativamente $(\mathrm{P}<0,05)$ menos gás quando incluídas em proporções acima de $50 \%$. A substituição total do farelo de soja por todas as tortas proporcionou menor produção total de gases $(124,108$, 97, 95 e $104 \mathrm{~mL} / \mathrm{g}$ MS (erro padrão $(\mathrm{EP})=5,41$ ) respectivamente para o farelo de soja e as tortas de algodão, dendê, mamona, pinhão manso I e pinhão manso II). 
Tabela 2 - Composição centesimal $(\mathrm{g} / \mathrm{Kg})$ das dietas experimentais

\begin{tabular}{|c|c|c|c|c|c|}
\hline Torta & Nível & Tifton & $\begin{array}{c}\text { Milho + } \\
\text { MM }^{1}\end{array}$ & $\begin{array}{c}\text { Farelo } \\
\text { de soja }\end{array}$ & Torta \\
\hline \multirow{4}{*}{ Algodão } & 25 & 0,70 & 0,16 & 0,09 & 0,05 \\
\hline & 50 & 0,70 & 0,15 & 0,06 & 0,09 \\
\hline & 75 & 0,70 & 0,14 & 0,03 & 0,14 \\
\hline & 100 & 0,69 & 0,13 & - & 0,18 \\
\hline \multirow{4}{*}{ Dendê } & 25 & 0,70 & 0,15 & 0,09 & 0,07 \\
\hline & 50 & 0,70 & 0,11 & 0,06 & 0,13 \\
\hline & 75 & 0,70 & 0,07 & 0,03 & 0,20 \\
\hline & 100 & 0,69 & 0,05 & - & 0,26 \\
\hline \multirow{4}{*}{ Mamona } & 25 & 0,70 & 0,17 & 0,09 & 0,04 \\
\hline & 50 & 0,70 & 0,16 & 0,06 & 0,09 \\
\hline & 75 & 0,71 & 0,14 & 0,03 & 0,13 \\
\hline & 100 & 0,70 & 0,12 & - & 0,17 \\
\hline \multirow{4}{*}{ Pinhão manso $\mathrm{I}^{2}$} & 25 & 0,70 & 0,14 & 0,09 & 0,07 \\
\hline & 50 & 0,70 & 0,11 & 0,06 & 0,14 \\
\hline & 75 & 0,70 & 0,07 & 0,03 & 0,21 \\
\hline & 100 & 0,69 & 0,04 & - & 0,27 \\
\hline \multirow{4}{*}{ Pinhão manso II $^{2}$} & 25 & 0,70 & 0,15 & 0,09 & 0,06 \\
\hline & 50 & 0,70 & 0,13 & 0,06 & 0,12 \\
\hline & 75 & 0,70 & 0,10 & 0,03 & 0,18 \\
\hline & 100 & 0,70 & 0,07 & - & 0,24 \\
\hline \multicolumn{2}{|l|}{ Farelo de soja } & 0,69 & 0,19 & 0,12 & - \\
\hline
\end{tabular}

${ }^{1} \mathrm{MM}=$ mistura mineral comercial, ${ }^{2}$ diferentes procedências

A MOVD média foi de 965 g/Kg MS (EP = 5,2) e o fator de partição foi semelhante entre todos os substratos estudados (3,6 mg MOVD/mL (EP = 0,44)). A produção de metano foi significativamente afetada pela inclusão das tortas. $\mathrm{O}$ farelo de soja apresentou produção de metano de 15,3 mL/g MOVD, enquanto que as tortas apresentaram produção de metano de 13,4; 11,1 11,8; 9,5 e $13,2 \mathrm{~mL} / \mathrm{g}$ MOVD $(\mathrm{EP}=0,86)$ respectivamente (algodão, dendê, mamona, pinhão manso I e pinhão manso II). Foi observada uma correlação negativa ( $\mathrm{P}<$ $0,05)$ entre o fator de partição de a produção de metano $\left(\mathrm{y}=-3,05+24,68, \mathrm{r}^{2}=0,535\right)$.

\section{Considerações finais}

As tortas e farelos oriundos da produção de biodiesel apresentam características nutricionais adequadas para inclusão na dieta de ruminantes, entretanto cuidados devem ser observados quanto a possíveis efeitos deletérios devido à presença de metabólitos bioativos em alguns materiais. Recomendase o estudo criterioso para a introdução segura destes subprodutos na cadeia produtiva.
A introdução de tortas com elevado teor de gordura nas dietas de ruminantes pode auxiliar na mitigação de metano entérico, e a produção de algumas oleaginosas pode contribuir com o seqüestro de carbono pelos solos de Cerrado na recuperação de pastagens, reduzindo a necessidade de desmatamentos.

\section{Literatura Citada}

ABDALLA, A.L.; LONGO, C.; BUENO, I.C.S. et al. Methane production and microbial evaluation by q-PCR of in vitro incubations of tannin-rich plants. Microbial Ecology in Health and Disease, v.19, n.1, p.32, 2007. Apresentado a Conference on Gastrointestinal Function, 2007, Chicago.

ABDALLA, A.L.; LONGO, C.; HUMMEL, J. et al. Effects of tanniniferous plants on in vitro enteric methane and other rumen fermentation products. In: GREENHOUSE GASES AND ANIMAL AGRICULTURE CONFERENCE, 3., 2007, Christchurch. Australian Journal of Experimental Agriculture. East Melbourne : CSIRO, 2008. v. 48. Abdalla et al. (2007: 3GGAA

ALMEIDA, R.S. Substituição parcial da uréia por diferentes níveis de farelo de babaçu na alimentação de vacas leiteiras. Imperatriz: Faculdade de Imperatriz, 2005. 27p. Trabalho (Graduação em Zootecnia) - Faculdade de Imperatriz FACIMP, 2005.

ARRIEL, N.H.C.; VIEIRA, D.J.; FIRMINO, P.T. Situação atual e perspectivas da cultura do gergelim no Brasil. In: QUEIRÓZ, M.A.; GOEDERT, C.O.; RAMOS, S.R.R. (Ed.). Recursos genéticos e melhoramento de plantas para o nordeste brasileiro. (on line). Versão 1.0. Petrolina: Embrapa Semi-Árido; Brasília-DF: Embrapa Recursos Genéticos e Biotecnologia, 1999. Disponível em: http://www.cpatsa.embrapa.br. 05 maio 2008.

ALBUQUERQUE, N.I. Emprego do babaçu (Orbignya phalerata) como fonte energética para catetos (Tayassu tajacu). Piracicaba: Centro de Energia Nuclear na Agricultura, 2006. 80p. Tese (Doutorado em Ciências) Centro de Energia Nuclear na Agricultura, 2006.

BALBINOT, N.S.; SCHNEIDER, R.C.S.; RODRIGUEZ, A.A.L. et al. Aproveitamento dos resíduos da produção de oleaginosas e da extração de óleo. Montevideo: AIDIS, 2006. Disponível em:

http://www.bvsde.paho.org/bvsaidis/uruguay30/BR05423_B albinot.pdf. 05 maio 2008.

BARBOSA, F.A. Alimentos na nutrição de bovinos. Portal Agronomia. Disponível em: http://www.agronomia.com.br/conteudo/artigos/artigos_nutr icao_bovinos.htm. 05 maio 2008.

BARROS, G.S.A.C.; SILVA, A.P.; PONCHIO, L.A. et al. Custos de produção de biodiesel no Brasil. Revista de Política Agrícola, v.15, n.3, p.36-50, 2006.

BAYER, C.; MARTIN-NETO, L.; MIELNICZUK, J. et al. Carbon sequestration in two Brazilian Cerrado soils under no-till. Soil \& Tillage Research, v.86, p.237-245, 2006.

BIODIESEL BR.COM. Tudo sobre biodiesel. Curitiba, 2008. Disponível

em: http://www.biodieselbr.com/biodiesel/biodiesel.htm. 05maio 2008.

BRASIL. Lei 11.097, de 13 de janeiro de 2003. Dispõe sobre a criação do Programa Nacional de Produção e Uso de 
Biodiesel e sobre a adição de biodiesel ao óleo diesel. Disponível em: http://www.anp.gov.br. 05 maio 2008.

BUENO, I.C.S.; VITTI, D.M.S.S.; LOUVANDINI, H. et al. A new approach for in vitro bioassay to measure tannin biological effects based on a gas production technique. Animal Feed Science and Technology, v.41, p.153-170, 2008.

CAI, Y.F.; ZHANG, H.; ZENG, Y. et al. An optimized gossypol high-performance liquid chromatography assay and its application in evaluation of different gland genotypes of cotton. Journal of Biosciences, v.29, p.67-71, 2004.

CARVALHO, G.G.P.; PIRES, A.J.V.; SILVA, R.R. et al. Comportamento ingestivo de ovinos alimentados com dietas compostas de silagem de capim-elefante amonizada ou não e subprodutos agroindustriais. Revista Brasileira de Zootecnia, v.35, n.4, p.-1805-1812, 2006. Suplemento.

CERRATE, S.; YAN, F.; WANG, Z. et al. Evaluation of glycerine from biodiesel production as a feed ingredient for broilers. International Journal of Poultry Science, v.5, n.11, p.1001-1007, 2006.

COSTA, F.X.; SEVERINO, L.S.; BELTRÃO, N.E.M. et al. Avaliação de teores químicos na torta de mamona. Revista de Biologia e Ciências da Terra, v.4, n.2, 2004. Disponível em:

http://www.uepb.edu.br/eduep/rbct/sumarios/pdf/tortamamo na.pdf. 05 maio 2008.

EVANGELISTA, A.R.; LOPES, J.; ABREU, J.G. et al. Avaliação da composição química de tortas de amendoim e mamona obtidos por extração com etanol. In: CONGRESSO DA REDE BRASILEIRA DE TECNOLOGIA DE BIODIESEL, 2., 2007, Brasília. Brasília: ABIPTI, 2007. Disponível em: http://www.biodiesel.gov.br/docs/congresso2007/producao/ 7.pdf. 05 maio 2008.

GARCIA, J.A.S.; VIEIRA, P.F.; CECON, P.R. et al. Desempenho de bovinos leiteiros em fase de crescimento alimentados com farelo de girassol. Ciência Animal Brasileira, v.7, n.3, p.223-233, 2006.

GRAINGER, C. GIA methane: increasing fat can reduce methane emissions. GIA Newsletter. Department of Primary Industries, march 2008.

JARDIM, W.R. Alimentos e alimentação do gado bovino. São Paulo: Agronômica Ceres, 1976. 338p.

KEARL, L.C. Nutrient requirements of ruminants in developing countries. Logon, Utah: International Feed Stuffs Institute. Utah Agriculture Experimental Station. Utah State University, 1982. p.45-58.

LONGO, C.; BUENO, I.C.S.; NOZELLA, E.F. et al. The influence of head-space and inoculum dilution on in vitro ruminal methane measurements. International Congress Series, v.1293, p.62-65, 2006.

LONGO, C.; LIEBICH, J.; JANZIK, I. et al. Effects of tanniniferous plants on rumen methanogens and fibrobacter succinogenes populations in vitro. In: GREENHOUSE GASES AND ANIMAL AGRICULTURE CONFERENCE, 3., 2007, Christchurch. Programme \& Abstract Book. Christchurch, 2007. p.65.

LOUVADINI, H.; NUNES, G.A.; GARCIA, J.A.S. et al. Desempenho, características de carcaça e constituintes corporais de ovinos Santa Inês alimentados com farelo de girassol em substituição ao farelo de soja na dieta. Revista Brasileira de Zootecnia, v.36, n.3, p.603-609, 2007.

MAKKAR, H.P.S.; BECKER, K. Plant toxins and detoxification methods to improve feed quality of tropical seeds - Review.
Asian-Australasian Journal of Animal Sciences, v.12, p.467480, 1999.

MAKKAR, H.P.S.; ADERIBIGBE, A.O.; BECKER, K. Comparative evaluation of non-toxic and toxic varieties of Jatropha curcas for chemical composition, digestibility, protein degradability and toxic factors. Food Chemistry, v.62, p.207-215, 1998.

MORRISON, F.B. Alimentos e alimentação dos animais. 2.ed. São Paulo: Edições Melhoramentos, 1966. 892p.

NEIVA JÚNIOR, A.P.; VAN CLEEF, E.H.C.B.; PARDO, R.M.P. et al. Subprodutos agroindustriais do biodiesel na alimentação de ruminantes. In: CONGRESSO DA REDE BRASILEIRA DE TECNOLOGIA DE BIODIESEL, 2., 2007, Brasília. Brasília: ABIPTI, 2007. Disponível em: http://www.biodiesel.gov.br/docs/congresso2007/coproduto/ 22.pdf. 05 maio 2008.

PAZIANI, S.F.; BERCHIELLI, T.T.; ANDRADE, P. Digestibilidade e degradabilidade de rações à base de milho desintegrado com palha e sabugo em diferentes graus de moagem. Revista Brasileira de Zootecnia, v.30, n.5, p.16301638, 2001.

PEKKARINEN, S.S.; HEINONEN, I.M.; HOPIA, A.I. Flavonoids quercetin, myricetin, kaemferol and catechin as antioxidants in methyl linoleate. Journal of the Science of Food and Agriculture, v.79, n.4, p.499-506, 1999.

PETROBIO. Biodiesel: Viabilidade econômica. Ribeirão Preto, 2005. Disponível em:

http://www.plantebiodiesel.com.br/MANUAIS\%20DO\%20 CD/27\%20-\%20BIODIESEL\%20-

\%20VIABILIDADE\%20ECONOMICA-

para\%20100000\%20Litros\%20de\%20Biodiesel\%20por\%20 dia.pdf. 05 maio 2008.

PINA, D.S.; VALADARES FILHO, S.C.; VALADARES, R.F.D. et al. Consumo e digestibilidade aparente total dos nutrientes, produção e composição do leite de vacas alimentadas com dietas contendo diferentes fontes de proteína. Revista Brasileira de Zootecnia, v.35, n.4, p.1543-1551, 2006.

REYES, G.C.; KODA, R.T. Development of a simple, rapid and reproducible HPLC assay for the simultaneous determination of hypericins and stabilized hyperforin in commercial St. John's Wort preparations. Journal of Pharmaceutical and Biomedical Analysis, v.26, p.959-965, 2001.

RIBEIRO, G.M.; SAMPAIO, A.A.M.; FERNANDES, A.R.M. et al. Efeito da fonte protéica e do processamento físico do concentrado sobre a terminação de bovinos jovens confinados e o impacto ambiental dos dejetos. Revista Brasileira de Zootecnia, v.36, n.6, p.2082-2091, 2007. Suplemento.

SCHRÖDER, A.; SÜDEKUM, K.-H. Glycerol as a by-product of biodiesel production in diets for ruminants. In: INTERNATIONAL RAPESEED CONGRESS, 10., 1999, Canberra. Gosford, Australia: Regional Institute, 1999. paper 241. Disponível em: http://www.regional.org.au/au/gcirc/1/241.htm. 05 maio 2008.

SILVA, H.G.O.; PIRES, A.J.V.; SILVA, F.F. et al. Digestibilidade aparente de dietas contendo farelo de cacau ou torta de dendê em cabras lactantes. Pesquisa Agropecuária Brasileira, v.40, n.4, p.405-411, 2005a.

SILVA, H.G.O.; PIRES, A.J.V.; SILVA, F.F. et al. Farelo de cacau (Theobroma cacao L.) e torta de dendê (Elaeis guineensis, Jacq) na alimentação de cabras em lactação: consumo e produção de leite. Revista Brasileira de Zootecnia, v.34, n.5, p.1786-1794, 2005b. 
SOUSA JUNIOR, A.; OLIVEIRA, M.E.; ALVES, A.A. et al. Digestibilidade de dietas contendo farelo de babaçu para ovinos em terminação. Archivos de Zootecnia, v.56, n.216, p.967-970, 2007.

STORCK BIODIESEL. O que é o biodiesel? Curitiba. Disponível em: www.storckbiodiesel.com.br. 05 maio 2008.

UNIVERSIDADE DE AÇORES. Energia renováveis. Bio combustíveis. Disponível em: http://www.lamtecid.com/energias/biocombustiveis.php. 05 maio 2008.
VALADARES FILHO, S.C.; ROCHA JÚNIOR, V.R.; CAPPELLE, E.R. (Ed.). Tabelas brasileiras de composição de alimentos para bovinos. Viçosa; UFV; DZO; DPI, 2001. 297p.

VINCENT, I.C.; HILL, R.; CAMPLING, R.C. A note on the use of rapeseed, sunflower and soybean meals as protein sources in compound foods for milking cattle. Animal Production, v.50, n.3, p.541-543, 1990. 